
\title{
25 Research Soure \\ Epicardial adipose tissue thickness as a predictor of gestational diabetes mellitus: a prospective cohort study
}

Jing Liu

The First Affiliated Hospital of China Medical University

Guang Song

Shengjing Hospital of China Medical University

Tao Meng ( $\nabla$ mengtao201011@163.com)

The First Affiliated Hospital of China Medical University https://orcid.org/0000-0002-9669-3387

Ge Zhao

The First Affiliated Hospital of China Medical University

Research article

Keywords: Gestational diabetes mellitus, Epicardial adipose tissue, Prediction, Echocardiography

Posted Date: December 9th, 2019

DOI: https://doi.org/10.21203/rs.2.18524/v1

License: @ (i) This work is licensed under a Creative Commons Attribution 4.0 International License.

Read Full License 


\section{Abstract}

\section{Background}

Gestational diabetes mellitus (GDM), the most common metabolic disorder of pregnancy, is a long term risk of comorbidities for maternal and neonatal. The study aimed to assess the association between the echocardiographic epicardial adipose tissue (EAT) and the risk for gestational diabetes mellitus (GDM) in the early second trimester.

\section{Methods}

Singleton pregnancies were enrolled in this study between September 2017 and January 2019 during their 16-20 gestational week. Odds ratio (OR) and 95\% confidence intervals (Cls) of individual maternal factors as potential predictors for GDM were calculated using generalized linear models. The receiveroperating-characteristic (ROC) analysis was conducted to assess the discriminative capacity of any individual maternal factor in predicting GDM.

\section{Results}

69 GDM and 420 normal women were included in the main analysis. Multivariate regression analysis revealed that EAT thickness $(\mathrm{OR}=1.96,95 \% \mathrm{Cl}: 1.50-2.55)$ and high-density lipoprotein cholesterol $(\mathrm{OR}=$ 0.21 , 95\% Cl: $0.05-0.84)$ were associated with the presence of GDM $(P<0.05)$. Meanwhile, EAT thickness was associated with adverse outcomes (including large for gestational age, neonatal hypoglycemia, admission to neonatal intensive care unit, preterm delivery, and hyperbilirubinemia) in the GDM group ( $P<$ 0.05). ROC analysis revealed that the area under curve was 0.698 and the cutoff value is $6.77 \mathrm{~mm}$ only using EAT thickness. After added high-density lipoprotein cholesterol into the analysis, the area under curve was increase into 0.713 .

\section{Conclusions}

Echocardiographic EAT thickness is positively and significantly associated with GDM risk and adverse outcomes related to GDM. Echocardiographic EAT is a simple method to predict the development of GDM prior to actual clinical diagnosis. This method provides a new early window of opportunity to implement primary prevention strategies to prevent GDM and reduce the related adverse maternal and perinatal outcomes.

\section{Background}

Gestational diabetes mellitus (GDM), the most common metabolic disorder of pregnancy, is defined as "the type of glucose intolerance that develops in the second and third trimester of pregnancy, resulting in hyperglycemia of variable severity" [1]. The offspring of women with GDM are at an increased risk of macrosomia, neonatal hypoglycemia, and hyperbilirubinemia. The prevalence of GDM varies from 1$20 \%$, and is rising worldwide, parallel to the increment in the prevalence of obesity and type 2 diabetes 
mellitus (T2DM) [2]. As reported before, the prevalence of GDM in a population of pregnant women usually reflects the prevalence of T2DM in that population [3].

It is important to predict GDM early in pregnancy to enable early interventions to prevent GDM and reduce the adverse maternal and perinatal outcomes. There are currently no established guidelines for the prediction of GDM and no effective modalities for the prevention of its future development prior to actual diagnosis.

Overweight/obesity is a main risk factor for GDM [4]. Body mass index (BMI) is a broad measurement of body fat, and clinicians usually use BMI to assess maternal obesity during pregnancy. However, BMI can't reflect the accumulation and mass of fat very sensitively, especially visceral adipose tissue (VAT) [5]. The previous study found BMI may not be a good predictor for GDM, particularly around the first trimester [6, 7]. Recently, a promising ultrasound parameter, epicardial adipose tissue (EAT), has emerged interest to clinical doctors. EAT is the visceral heart adipose and has the lipogenic capacity [8]. EAT thickness is an independent predictor of visceral adiposity [9], showed a close relationship with metabolic syndrome and diabetes $[10,11]$. Echocardiography is a simple method to measure EAT thickness, which can nicely reflect VAT. Also, lipid profiles were enrolled in this study, which were popular predictors for GDM $[12,13]$. This study was aimed to investigate the association between the EAT thickness and GDM, and assess the effectiveness of EAT thickness as a predictor for GDM at 16-20 gestational week (GW).

\section{Methods}

\section{Study design, setting and population}

This prospective cohort study was conducted at the First Affiliated Hospital of China Medical University. All participants were admitted to our obstetric clinic between September 2017 and January 2019. All participants provided written informed consent and the study protocol was approved by the Medical Ethics Review Board of China Medical University (Shenyang, Liaoning, China).

\section{Inclusion and exclusion criteria}

Participants were eligible: (1) a singleton pregnancy; (2) had their first pregnancy visit during 16-20 GW. Gestational age was determined by ultrasound within 3 months of pregnancy confirmation; (3) signed the informed consent and provided complete medical history. Participants were not eligible if they had a history of (1) diabetes; (2) hypertension; (3) cardiovascular diseases.

\section{Data collection during 16-20 GW}

Anthropometric parameters such as weight, height, heart rate, systolic blood pressure, and diastolic blood pressure were measured, and BMI was calculated [14].

A peripheral blood sample of the participants was collected in a vacutainer collection tube before $20 \mathrm{GW}$. The lipid profile including triglyceride, total cholesterol, high-density lipoprotein cholesterol (HDL-C), and 
low-density lipoprotein cholesterol (LDL-C) were measured using an auto-analyzer (AU1000; Olympus, Tokyo, Japan).

Echocardiographic evaluation was performed in the left lateral position using a Philips iE33 system (Philips Medical Systems, Bothell, WA, USA) and a 1.5/5 MHz phased array probe with a frame rate of 60-90 fps. All images and measurements were obtained from standard views according to the recommendations of the American Society of Echocardiography for chamber quantification $[15,16]$. All images were digitally stored and analyzed offline using customized software (Qlab; Philips Medical Systems)

The left ventricle end-diastolic dimension was obtained in the parasternal long-axis view. Left ventricle end-diastolic volume and end-systolic volume were obtained using the biplane modified Simpson's method. Stroke volume, cardiac output, and left ventricle ejection fraction were used as standard indexes of left ventricle systolic function. The peak of early diastolic velocity ( $E$ wave) and the peak of late diastolic velocity ( $A$ wave) across the mitral valve were obtained. The ratio between them (E/A) was used as a standard index of left ventricular diastolic function.

\section{Data collection during 24-28 GW}

GDM was diagnosed according to the International Association of Diabetes and Pregnancy Study Groups [17]. A diagnosis of GDM was made when one or more of the test parameters equaled or exceeded the following cut points: fasting $5.1 \mathrm{mmol} / \mathrm{L}, 1-\mathrm{h} 10.0 \mathrm{mmol} / \mathrm{L}$, or 2-h $8.5 \mathrm{mmol} / \mathrm{L}$.

\section{Postpartum Follow up}

Adverse GDM-associated outcomes were recorded, including large for gestational age, neonatal hypoglycemia, admission to neonatal intensive care unit (NICU), preterm delivery, and hyperbilirubinemia $[4,18]$.

\section{Statistical analysis}

Statistical analysis was performed using STATA version 14.0 software. Continuous parameters were expressed as the mean \pm standard deviation. Non-normally distributed parameters were expressed as the median (interquartile range). Differences of normally distributed continuous parameters between groups were analyzed using the independent-samples $t$-test. Differences of non-normally distributed parameters between groups were analyzed using the Mann-Whitney $U$ test. Differences of categorial parameters between groups were analyzed using Pearson's chi-squared test. Odds ratio (OR) and 95\% confidence intervals (Cls) of individual maternal factors as potential predictors for GDM were calculated using generalized linear models. The receiver-operating-characteristic (ROC) analysis was conducted to assess the discriminative capacity of any individual maternal factor in predicting GDM. A two-tailed $P<0.05$ was used to define statistical significance. 


\section{Result}

\section{Comparison of Clinical data}

A total of 489 mothers met eligibility criteria were included in the main analysis, including 69 GDM and 420 normal women (Figure 1). Table 1 revealed that the baseline of the clinical characters of participants between the GDM and control groups. The difference between the two groups in the maternal age, BMI, and lipid profiles (triglyceride, total cholesterol, and HDL-C) were statistically significant $(P<0.05)$.

\section{Comparison of echocardiographic data}

Table 2 revealed that EAT thickness significantly increased in the GDM group compared with the control group $(P<0.05)$. The other clinical and echocardiographic parameters were not significantly different between the two groups $(P>0.05)$.

\section{Regression analysis for the presence of GDM}

The results of all regression analyses were summarized in Table 3 . Univariate regression analysis revealed that maternal age $(\mathrm{OR}=1.08,95 \% \mathrm{Cl}: 1.01-1.17), \mathrm{BMI}(\mathrm{OR}=1.07,95 \% \mathrm{Cl}: 1.00-1.14)$, triglyceride $(\mathrm{OR}=1.44,95 \% \mathrm{Cl}: 1.02-2.04)$, total cholesterol $(\mathrm{OR}=1.40,95 \% \mathrm{Cl}: 1.04-1.88), \mathrm{HDL}-\mathrm{C}(\mathrm{OR}=0.17,95 \% \mathrm{Cl}$ : $0.04-0.62)$, and EAT thickness (OR $=2.06,95 \% \mathrm{Cl}: 1.60-2.65)$ were associated with the presence of GDM $(P<0.05)$. Multivariate regression analysis revealed that $\mathrm{HDL}-\mathrm{C}(\mathrm{OR}=0.21,95 \% \mathrm{Cl}: 0.05-0.84)$ and EAT thickness $(\mathrm{OR}=1.96,95 \% \mathrm{Cl}: 1.50-2.55)$ were associated with the presence of $\operatorname{GDM}(P<0.1)$.

\section{Comparison of the adverse outcomes between the groups}

Table 4 showed that the risk of adverse outcomes, including large for gestational age, neonatal hypoglycemia, admission to NICU, preterm delivery, and hyperbilirubinemia, increased in the GDM group compared with the control group $(P<0.05)$.

\section{Association of EAT thickness with adverse outcomes in the GDM group}

Table 5 showed that EAT thickness significantly increased in the GDM group with adverse outcomes compared with the control group without adverse outcomes $(P<0.05)$. Regression analysis revealed that EAT thickness was risk factor for large for gestational age (OR $=8.94,95 \% \mathrm{Cl}: 2.74-29.22)$, neonatal hypoglycemia (OR $=109.51,95 \% \mathrm{Cl}: 1.32-9076.10)$, admission to NICU (OR $=10.82,95 \% \mathrm{Cl}: 2.98-39.22)$, preterm delivery $(\mathrm{OR}=10.90,95 \% \mathrm{Cl}: 2.56-46.45)$, and hyperbilirubinemia $(\mathrm{OR}=3.97,95 \% \mathrm{Cl}: 1.24-12.63)$ $(P<0.05)$. In total, EAT thickness was a risk factor for the GDM with adverse outcomes $(\mathrm{OR}=70.07$, 95\%Cl: 5.66-867.30, $P<0.05)$.

\section{ROC analysis}

We performed an ROC analysis to verify whether EAT thickness could predict GDM. The ROC curve was shown in Figure 2. The area under curve was 0.698 (95\% Cl: $0.629-0.767)$ and the cutoff value is 
$6.77 \mathrm{~mm}$. If HDL-C was added into the ROC analysis, the area under curve was increase into $0.713(95 \% \mathrm{Cl}$ : $0.643-0.782)$.

\section{Discussion}

Predict GDM as early as possible is a very important goal pursued by researchers over the years, which would allow for early lifestyle changes and/or nutritional interventions to prevent GDM. Unfortunately, pregnancy is a complex and dynamic process, involving profound changes in energy and nutrient metabolism to sustain fetal development and growth, and to meet the requirements of labor and lactation. Until now, there are no established guidelines for the prediction of GDM.

VAT plays a leading part in the development of obesity which is an important risk factor of GDM. As a special type of VAT, EAT has its multifaced functions. More researchers focused on the adverse effects of EAT which has been confirmed as a diabetic risk marker [11]. Two cross-sectional studies with limited samples found the difference of EAT thickness between the GDM and the control group at the late second trimester (24-28 GW) [19, 20]. However, whether EAT has a significant difference in the early second trimester and then EAT becomes a predictor for GDM are unclear.

In this study, the result revealed that EAT thickness significantly increased in the GDM group compared with the control group during 16-20 GW. Meanwhile, higher EAT thickness was associated with the adverse outcomes in GDM patients. We proposed some mechanisms for the increasing EAT thickness in the GDM patients base on the existing research:

\section{Insulin resistance (IR)}

EAT as a lipid-storing depot and endocrine organ can secreting adipokines. IR is the main mechanism of GDM [21], which may be affected by the amount of adipose tissue before pregnancy and/or its increase during pregnancy. Higher retinol binding protein 4 (RBP4, as insulin resistance) and lower adiponectin (as insulin-sensitizer), which were secreted by adipose including EAT, cause insulin resistance in the GDM before $16 \mathrm{GW}[22,23]$.

\section{Inflammatory}

EAT expresses and secretes pro-inflammatory and anti-inflammatory adipokines and cytokines [24]. The first-second trimester released higher pro-inflammatory adipokines (RBP4, hs-CRP, fatty acid-binding protein-4, leptin, and visfatin) and lower anti-inflammatory adipokines (omentin-1 and adiponectin) may participate in the chronic low-grade inflammation state which has been confirmed to be associated with GDM [23]. Additionally, tumor necrosis factor (TNF), as a cytokine secreted by EFT was increasing in GDM patients [25]. In summary, EAT-induced pro-inflammatory milieu trigger physiopathological mechanisms such as obesity, insulin resistance, and disturbed insulin signaling cascade [26, 27].

In this study, the result also showed that maternal HDL-C is negatively associated with the risk for GDM and can increase the predicted performance of EAT thickness. Several studies showed similar results [12, 
13, 28-31]. The mechanism may be that the progressive increase in VAT causes insulin resistance in liver and adipose tissue, and, as a result, causes low-level HDL-C [32, 33].

Echocardiography is inexpensive and noninvasive. Using echocardiography to measure EAT thickness is not only easy to visualized and measured, but also accurate and reproducible [34]. Echocardiographic EAT has a close relationship with IR and inflammatory, can reflect the metabolic effects of IR [35]. Moreover, in women who are normoglycaemic before pregnancy but go on to develop GDM in the late gestation, there is an evidence of decreased peripheral insulin sensitivity before conception [36]. Thus, the EAT thickness increased before hyperglycemia shows up, which due to the insulin response is inadequate as the IR increases in late pregnancy. In the early second trimester, measure EAT thickness and HDL-C can evaluate the risk of GDM which may help clinicians to develop appropriate treatment strategies.

Pregnancy can be viewed as a cardiovascular stress test in that the development of certain complications has the potential to reveal a woman's susceptibility for future vascular or metabolic disease [37]. The measurement of EAT provides us a new way to screen the high risk not only for GDM but also for other cardiovascular complications related to metabolic disease. The present data support the relationship between EAT and GDM. New studies with longer follow-up duration are needed to determine whether the high-risk people for GDM identified by EAT levels are related to T2DM and cardiovascular diseases, which allows us to implement preventive measures for this population.

In our study, participants are all Asian women. However, the race may be an important consideration when analyzing the relationship between EAT and disease risk [38]. Also, there are no data of inflammatory biomarkers which may be beneficial to the effectiveness of the EAT thickness model in the early second trimester.

\section{Conclusion}

Our findings indicate that echocardiographic EAT thickness is positively and significantly associated with GDM risk and adverse outcomes related to GDM. Echocardiographic EAT is a simple method to predict the development of GDM in the early second trimester. Further studies are needed to investigate the relationship between the EAT measurement during pregnancy and the presence of T2DM and cardiovascular diseases in their future life.

\section{Abbreviations}

BMI: Body mass index; Cls: Confidence intervals; GDM: Gestational diabetes mellitus; GW: Gestational week; HDL-C: High-density lipoprotein cholesterol; IR: Insulin resistance; LDL-C: Low-density lipoprotein cholesterol; OR: Odds ratio. T2DM: Type 2 diabetes mellitus; VAT: Visceral adipose tissue.

\section{Declarations}


None.

\section{Authors' contributions}

JL drafted the manuscript. GS involved in manuscript writing, data collection and data analysis. TM involved in project development and manuscript writing. GZ involved in data collection and data analysis. All authors read and approved the manuscript.

\section{Funding}

Supported by the National Natural Science Foundation of China (Grant No. 81871173). The funder had no role in the design of the study, collection, analysis, and interpretation of data, or in writing the manuscript.

\section{Availability of data and material}

The datasets used and/or analyzed during the current study are available from the corresponding author on reasonable request.

\section{Ethics approval and consent to participate}

This study obtained ethical approval from the Medical Ethics Review Board of China Medical University (Shenyang, Liaoning, China). All participants provided written informed consent.

\section{Consent for publication}

Not applicable.

\section{Competing interests}

The authors declare that they have no competing interests

\section{References}

1. care ADAJD: 2. Classification and diagnosis of diabetes. 2016, 39(Supplement 1):S13-S22.

2. Bevier WC, Jovanovic-Peterson L, Peterson CM: Pancreatic disorders of pregnancy. Diagnosis, management, and outcome of gestational diabetes. Endocrinol Metab Clin North Am 1995, 24(1):103-138.

3. Zhu Y, Zhang C: Prevalence of Gestational Diabetes and Risk of Progression to Type 2 Diabetes: a Global Perspective. Curr Diab Rep 2016, 16(1):7.

4. Mclntyre HD, Catalano P, Zhang C, Desoye G, Mathiesen ER, Damm P: Gestational diabetes mellitus. Nat Rev Dis Primers 2019, 5(1):47. 
5. Hamdy O, Porramatikul S, Al-Ozairi E: Metabolic obesity: the paradox between visceral and subcutaneous fat. Curr Diabetes Rev 2006, 2(4):367-373.

6. Correa PJ, Venegas P, Palmeiro Y, Albers D, Rice G, Roa J, Cortez J, Monckeberg M, Schepeler M, Osorio $\mathrm{E}$ et al: First trimester prediction of gestational diabetes mellitus using plasma biomarkers: a case-control study. J Perinat Med 2019, 47(2):161-168.

7. Kumru P, Arisoy R, Erdogdu E, Demirci O, Kavrut M, Ardic C, Aslaner N, Ozkoral A, Ertekin A: Prediction of gestational diabetes mellitus at first trimester in low-risk pregnancies. Taiwan J Obstet Gynecol 2016, 55(6):815-820.

8. Marchington JM, Pond CM: Site-specific properties of pericardial and epicardial adipose tissue: the effects of insulin and high-fat feeding on lipogenesis and the incorporation of fatty acids in vitro. Int J Obes 1990, 14(12):1013-1022.

9. lacobellis G, Willens HJ, Barbaro G, Sharma AM: Threshold values of high-risk echocardiographic epicardial fat thickness. Obesity (Silver Spring) 2008, 16(4):887-892.

10. Pierdomenico SD, Pierdomenico AM, Cuccurullo F, lacobellis G: Meta-analysis of the relation of echocardiographic epicardial adipose tissue thickness and the metabolic syndrome. Am J Cardiol 2013, 111(1):73-78.

11. Li Y, Liu B, Li Y, Jing X, Deng S, Yan Y, She Q: Epicardial fat tissue in patients with diabetes mellitus: a systematic review and meta-analysis. Cardiovasc Diabetol 2019, 18(1):3.

12. Li G, Kong L, Zhang L, Fan L, Su Y, Rose JC, Zhang W: Early Pregnancy Maternal Lipid Profiles and the Risk of Gestational Diabetes Mellitus Stratified for Body Mass Index. Reprod Sci 2015, 22(6):712717.

13. Zheng T, Ye W, Wang X, Li X, Zhang J, Little J, Zhou L, Zhang L: A simple model to predict risk of gestational diabetes mellitus from $\mathbf{8}$ to $\mathbf{2 0}$ weeks of gestation in Chinese women. BMC Pregnancy Childbirth 2019, 19(1):252.

14. Liu J, Song G, Meng T, Zhao G, Guo S: Weight retention at six weeks postpartum and the risk of gestational diabetes mellitus in a second pregnancy. BMC Pregnancy Childbirth 2019, 19(1):272.

15. Lang RM, Badano LP, Mor-Avi V, Afilalo J, Armstrong A, Ernande L, Flachskampf FA, Foster E, Goldstein SA, Kuznetsova $T$ et al: Recommendations for cardiac chamber quantification by echocardiography in adults: an update from the American Society of Echocardiography and the European Association of Cardiovascular Imaging. J Am Soc Echocardiogr 2015, 28(1):1-39 e14.

16. Song G, Liu J, Ren W, Qiao W, Zhang J, Zhan Y, Bi W: Reversible Changes of Left Atrial Function during Pregnancy Assessed by Two-Dimensional Speckle Tracking Echocardiography. PLoS One 2015, 10(5):e0125347.

17. Weinert LS: International Association of Diabetes and Pregnancy Study Groups recommendations on the diagnosis and classification of hyperglycemia in pregnancy: comment to the International Association of Diabetes and Pregnancy Study Groups Consensus Panel. Diabetes Care 2010, 33(7):e97; author reply e98. 
18. Szmuilowicz ED, Josefson JL, Metzger BE: Gestational Diabetes Mellitus. Endocrinol Metab Clin North Am 2019, 48(3):479-493.

19. Nar G, Inci S, Aksan G, Unal OK, Nar R, Soylu K: The relationship between epicardial fat thickness and gestational diabetes mellitus. Diabetology \& metabolic syndrome 2014, 6(1):120.

20. Yavuz A, Akkurt MO, Yalcin S, Karakoc G, Varol E, Sezik M: Second Trimester Fetal and Maternal Epicardial Fat Thickness in Gestational Diabetic Pregnancies. Hormone and metabolic research = Hormon- und Stoffwechselforschung = Hormones et metabolisme 2016, 48(9):595-600.

21. American Diabetes A: Diagnosis and classification of diabetes mellitus. Diabetes Care 2006, 29 Suppl 1(suppl 1):S43-48.

22. Ategbo JM, Grissa O, Yessoufou A, Hichami A, Dramane KL, Moutairou K, Miled A, Grissa A, Jerbi M, Tabka Z et al: Modulation of adipokines and cytokines in gestational diabetes and macrosomia. The Journal of clinical endocrinology and metabolism 2006, 91(10):4137-4143.

23. Lorenzo-Almoros A, Hang T, Peiro C, Soriano-Guillen L, Egido J, Tunon J, Lorenzo O: Predictive and diagnostic biomarkers for gestational diabetes and its associated metabolic and cardiovascular diseases. Cardiovasc Diabetol 2019, 18(1):140.

24. Baker AR, Silva NF, Quinn DW, Harte AL, Pagano D, Bonser RS, Kumar S, McTernan PG: Human epicardial adipose tissue expresses a pathogenic profile of adipocytokines in patients with cardiovascular disease. Cardiovasc Diabetol 2006, 5:1.

25. lacobellis G, Barbaro G: The double role of epicardial adipose tissue as pro- and anti-inflammatory organ. Hormone and metabolic research $=$ Hormon- und Stoffwechselforschung $=$ Hormones et metabolisme 2008, 40(7):442-445.

26. Hotamisligil GS, Peraldi P, Budavari A, Ellis R, White MF, Spiegelman BM: IRS-1-mediated inhibition of insulin receptor tyrosine kinase activity in TNF-alpha- and obesity-induced insulin resistance. Science 1996, 271(5249):665-668.

27. Kirwan JP, Varastehpour A, Jing M, Presley L, Shao J, Friedman JE, Catalano PM: Reversal of insulin resistance postpartum is linked to enhanced skeletal muscle insulin signaling. The Journal of clinical endocrinology and metabolism 2004, 89(9):4678-4684.

28. Savvidou M, Nelson SM, Makgoba M, Messow CM, Sattar N, Nicolaides K: First-trimester prediction of gestational diabetes mellitus: examining the potential of combining maternal characteristics and laboratory measures. Diabetes 2010, 59(12):3017-3022.

29. Ryckman KK, Spracklen CN, Smith CJ, Robinson JG, Saftlas AF: Maternal lipid levels during pregnancy and gestational diabetes: a systematic review and meta-analysis. BJOG 2015, 122(5):643-651.

30. Wang $\mathrm{D}$, Xu S, Chen H, Zhong L, Wang Z: The associations between triglyceride to high-density lipoprotein cholesterol ratios and the risks of gestational diabetes mellitus and large-for-gestationalage infant. Clin Endocrinol (Oxf) 2015, 83(4):490-497.

31. Jin WY, Lin SL, Hou RL, Chen XY, Han T, Jin Y, Tang L, Zhu ZW, Zhao ZY: Associations between maternal lipid profile and pregnancy complications and perinatal outcomes: a population-based 
study from China. BMC Pregnancy Childbirth 2016, 16:60.

32. Reaven GM: Banting lecture 1988. Role of insulin resistance in human disease. Diabetes 1988, 37(12):1595-1607.

33. Pascot A, Despres JP, Lemieux I, Bergeron J, Nadeau A, Prud'homme D, Tremblay A, Lemieux S: Contribution of visceral obesity to the deterioration of the metabolic risk profile in men with impaired glucose tolerance. Diabetologia 2000, 43(9):1126-1135.

34. lacobellis G, Willens HJ: Echocardiographic epicardial fat: a review of research and clinical applications. J Am Soc Echocardiogr 2009, 22(12):1311-1319; quiz 1417-1318.

35. Caliskan M, Caklili OT, Caliskan Z, Duran C, Ciftci FC, Avci E, Gullu H, Kulaksizoglu M, Koca H, Muderrisoglu H: Does gestational diabetes history increase epicardial fat and carotid intima media thickness? Echocardiography 2014, 31(10):1182-1187.

36. Catalano PM, Huston L, Amini SB, Kalhan SC: Longitudinal changes in glucose metabolism during pregnancy in obese women with normal glucose tolerance and gestational diabetes mellitus. $A m \mathrm{~J}$ Obstet Gynecol 1999, 180(4):903-916.

37. Williams D: Pregnancy: a stress test for life. Curr Opin Obstet Gynecol 2003, 15(6):465-471.

38. Salami SS, Tucciarone M, Bess R, Kolluru A, Szpunar S, Rosman H, Cohen G: Race and epicardial fat: the impact of anthropometric measurements, percent body fat and sex. Ethn Dis 2013, 23(3):281285.

\section{Tables}

Table 1 The baseline of clinical characters of participants

\begin{tabular}{lllc}
\hline & GDM $(\mathrm{n}=69)$ & Control $(\mathrm{n}=420)$ & $P$ \\
\hline Maternal age (years) & $33.90 \pm 3.21$ & $32.80 \pm 3.89$ & 0.014 \\
Height $(\mathrm{m})$ & $1.62 \pm 0.05$ & $1.63 \pm 0.05$ & 0.127 \\
Weight $(\mathrm{kg})$ & $61.31 \pm 8.28$ & $59.45 \pm 9.71$ & 0.134 \\
BMI $\left(\mathrm{kg} / \mathrm{m}^{2}\right)$ & $23.21 \pm 3.33$ & $22.40 \pm 3.82$ & 0.047 \\
Parity & $1(1-2)$ & $1(1-2)$ & 0.751 \\
Heart rate (beats/minute) & $73.93 \pm 5.83$ & $71.86 \pm 11.62$ & 0.149 \\
SBP $(\mathrm{mmHg})$ & $117.86 \pm 6.30$ & $116.37 \pm 9.11$ & 0.193 \\
DBP (mmHg) & $76.04 \pm 8.57$ & $74.97 \pm 7.10$ & 0.259 \\
Triglyceride (mmol/L) & $2.74 \pm 0.75$ & $2.53 \pm 0.74$ & 0.037 \\
Total cholesterol (mmol/L) & $6.42 \pm 0.88$ & $6.16 \pm 0.90$ & 0.025 \\
HDL-C (mmol/L) & $1.72 \pm 0.22$ & $1.79 \pm 0.19$ & 0.007 \\
LDL-C (mmol/L) & $3.39 \pm 0.62$ & $3.43 \pm 0.61$ & 0.621 \\
\hline
\end{tabular}

$B M I$, Body mass index; $D B P$, Diastolic blood pressure; GDM, Gestational diabetes mellitus; $H D L-C$, Highdensity lipoprotein cholesterol; $L D L-C$, Low-density lipoprotein cholesterol; $S B P$, Systolic blood pressure

Table 2 Echocardiographic characters of participants 


\begin{tabular}{lllr}
\hline & GDM $(\mathrm{n}=69)$ & Control $(\mathrm{n}=420)$ & $P$ \\
\hline LVDd (mm) & $43.99 \pm 2.54$ & $44.01 \pm 2.98$ & 0.955 \\
EDV (ml) & $88.07 \pm 10.48$ & $88.21 \pm 11.53$ & 0.924 \\
ESV (ml) & $30.77 \pm 4.59$ & $31.69 \pm 6.33$ & 0.249 \\
SV (ml) & $57.30 \pm 8.14$ & $56.53 \pm 8.92$ & 0.499 \\
CO (L/min) & $4.25 \pm 0.77$ & $4.06 \pm 0.91$ & 0.098 \\
LVEF (\%) & $65.00 \pm 3.86$ & $64.03 \pm 5.38$ & 0.152 \\
E wave (m/s) & $0.97 \pm 0.17$ & $0.99 \pm 0.20$ & 0.355 \\
A wave (m/s) & $0.51 \pm 0.08$ & $0.51 \pm 0.10$ & 0.994 \\
E/A & $1.92 \pm 0.35$ & $2.01 \pm 0.58$ & 0.214 \\
EAT thickness (mm) & $6.37 \pm 1.21$ & $5.46 \pm 1.15$ & $<0.001$ \\
\hline
\end{tabular}

$C O$, Cardiac output; EAT, Epicardial adipose tissue; EDV, End-diastolic volume; ESV, End-systolic volume; GDM, Gestational diabetes mellitus; $L V D d$, Left ventricle end-diastolic dimension; $L V E F$, Left ventricle ejection fraction; $S V$, Stroke volume

Table 3 Results of univariate and multivariate regression analysis for the presence of GDM

\begin{tabular}{lcrrrr}
\hline & \multicolumn{2}{c}{ Univariate regression } & & \multicolumn{2}{c}{ Multivariate regression } \\
\cline { 2 - 3 } & OR (95\%CI) & $P$ & OR (95\%CI) & $P$ \\
\hline Maternal age (years) & $1.08(1.01-1.17)$ & 0.028 & & $1.07(0.99-1.15)$ & 0.114 \\
BMI $\left(\mathrm{kg} / \mathrm{m}^{2}\right)$ & $1.07(1.00-1.14)$ & 0.049 & & $1.02(0.95-1.10)$ & 0.578 \\
Triglyceride (mmol/L) & $1.44(1.02-2.04)$ & 0.038 & & $1.35(0.94-1.94)$ & 0.102 \\
Total cholesterol (mmol/L) & $1.40(1.04-1.88)$ & 0.026 & & $1.30(0.95-1.79)$ & 0.104 \\
HDL-C $(\mathrm{mmol} / \mathrm{L})$ & $0.17(0.04-0.62)$ & 0.007 & & $0.21(0.05-0.84)$ & 0.027 \\
EAT thickness $(\mathrm{mm})$ & $2.06(1.60-2.65)$ & $<0.001$ & & $1.96(1.50-2.55)$ & $<0.001$ \\
\hline
\end{tabular}

$B M I$, Body mass index; CI, Confidence interval; EAT, Epicardial adipose tissue; GDM, Gestational diabetes mellitus; $H D L-C$, High-density lipoprotein cholesterol; OR, Odds ratio

Table 4 Comparison of the adverse outcomes between the two groups

\begin{tabular}{lllr}
\hline & GDM $(\mathrm{n}=69)$ & Control $(\mathrm{n}=420)$ & $P^{*}$ \\
\hline Total & $18 / 51$ & $54 / 366$ & 0.004 \\
Large for gestational age & $12 / 57$ & $38 / 382$ & 0.034 \\
Neonatal hypoglycemia & $5 / 64$ & $2 / 418$ & $<0.001$ \\
Admission to NICU & $12 / 57$ & $39 / 381$ & 0.041 \\
Preterm delivery & $9 / 60$ & $20 / 400$ & 0.007 \\
Hyperbilirubinemia & $5 / 64$ & $4 / 416$ & $<0.001$ \\
\hline
\end{tabular}

GDM, Gestational diabetes mellitus; NICU, Neonatal intensive care unit

Table 5 Association of EAT thickness with adverse outcomes in the GDM group 


\begin{tabular}{lllrrr}
\hline & With adverse outcomes & Without adverse outcomes & $P^{*}$ & OR (95\%CI) & $P^{\#}$ \\
\hline Total & $7.87 \pm 0.56$ & $5.85 \pm 0.90$ & $<0.001$ & $70.07(5.66-867.30)$ & 0.001 \\
Large for gestational age & $7.89 \pm 0.62$ & $6.05 \pm 1.06$ & $<0.001$ & $8.94(2.74-29.22)$ & $<0.001$ \\
Neonatal hypoglycemia & $8.37 \pm 0.36$ & $6.22 \pm 1.12$ & $<0.001$ & $109.51(1.32-9076.10)$ & 0.037 \\
Admission to NICU & $8.08 \pm 0.51$ & $6.08 \pm 1.05$ & $<0.001$ & $10.82(2.98-39.22)$ & $<0.001$ \\
Preterm delivery & $8.03 \pm 0.52$ & $6.12 \pm 1.09$ & $<0.001$ & $10.90(2.56-46.45)$ & 0.001 \\
Hyperbilirubinemia & $7.79 \pm 0.49$ & $6.26 \pm 1.19$ & 0.006 & $3.97(1.24-12.63)$ & 0.020 \\
\hline
\end{tabular}

$C I$, Confidence interval; EAT, Epicardial adipose tissue; GDM, Gestational diabetes mellitus; $N I C U$, Neonatal intensive care unit; $O R$, odds ratio

$P^{*}: P$-value of independent-samples $t$-test;

$P^{\#}$ : $P$-value of univariate regression between epicardial adipose tissue thickness and adverse outcomes using generalized linear models.

Figures 
Potential participants assessed for eligibility $(n=500)$

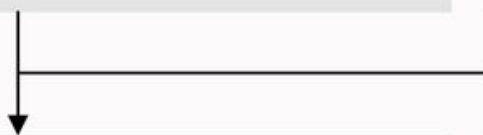

Dedined to participate $(n=4)$

Eligibility $(n=496)$
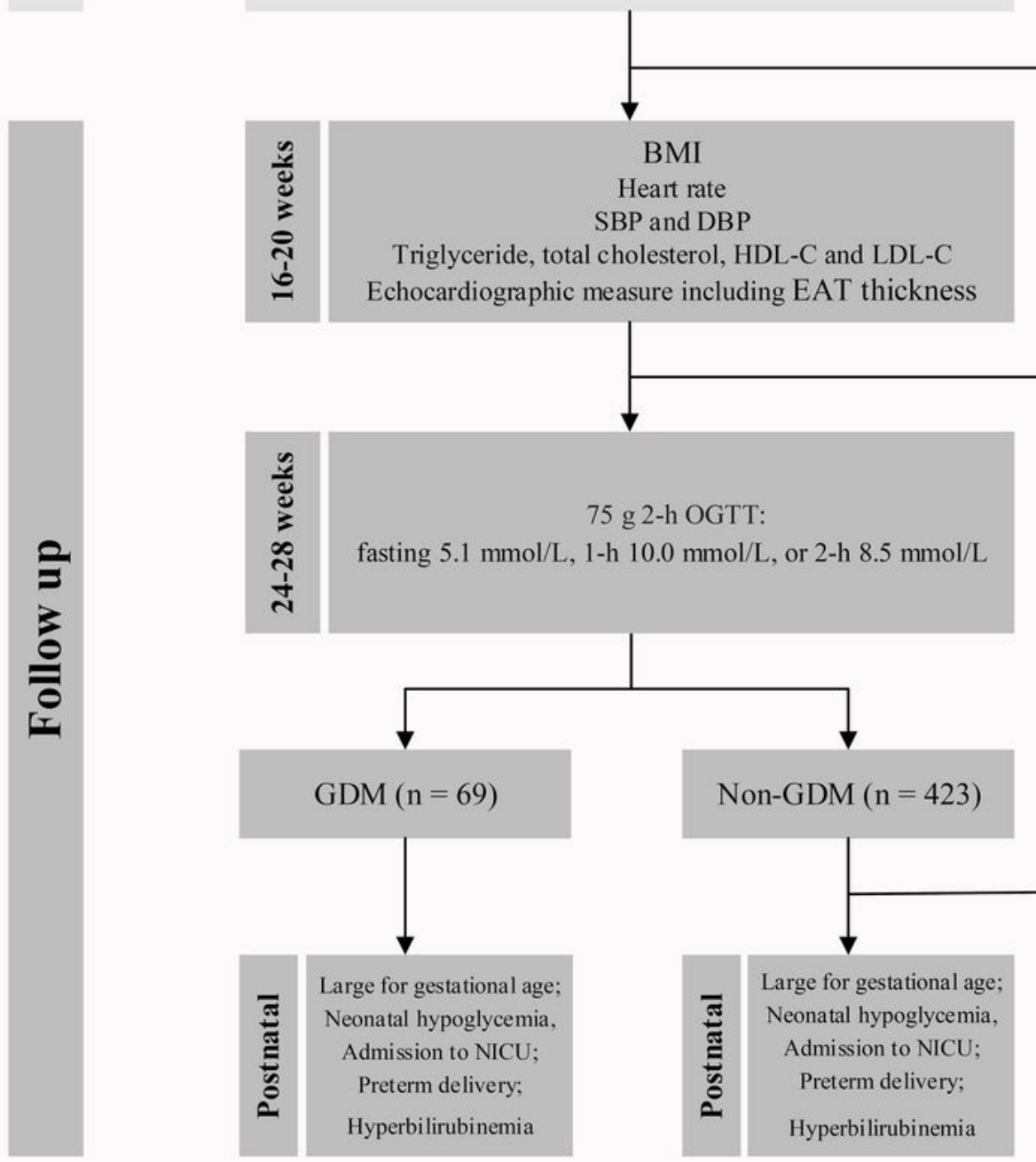

Miscarriage $(\mathrm{n}=3)$

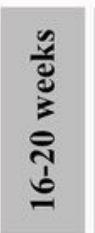

\section{BMI}

Heart rate

SBP and DBP

Triglyceride, total cholesterol, HDL-C and LDL-C

Echocardiographic measure including EAT thickness

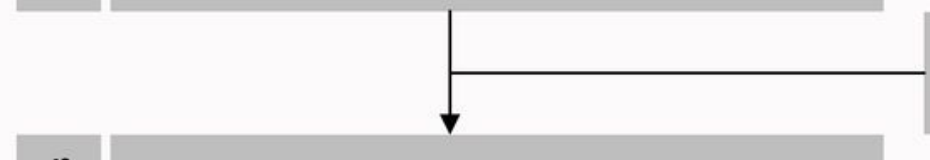

Lost to follow-up $(n=1)$ for abortion because of fetal malformation

$75 \mathrm{~g}$ 2-h OGTT:

fasting $5.1 \mathrm{mmol} / \mathrm{L}, 1-\mathrm{h} 10.0 \mathrm{mmol} / \mathrm{L}$, or $2-\mathrm{h} 8.5 \mathrm{mmol} / \mathrm{L}$

先
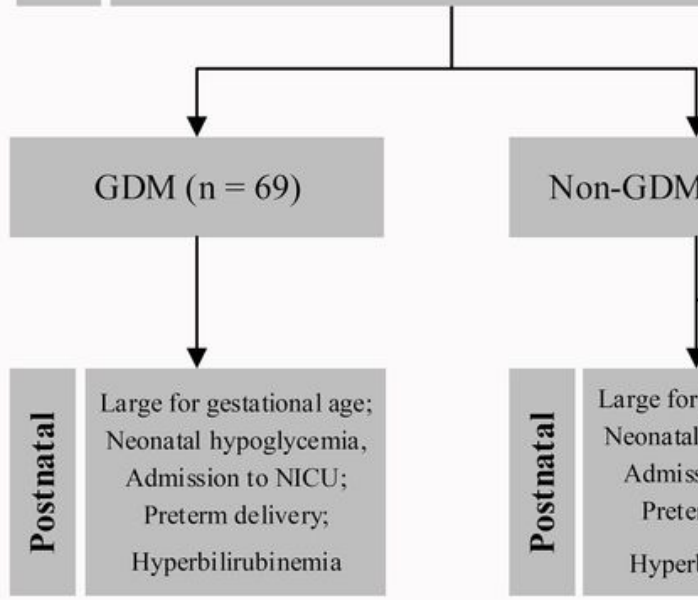

Non-GDM $(n=423)$

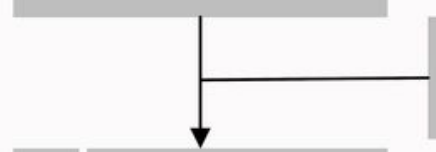

Lost to follow-up $(\mathrm{n}=3)$

Large for gestational age;

Neonatal hypoglycemia,

Admission to NICU;

Preterm delivery;

Hyperbilirubinemia
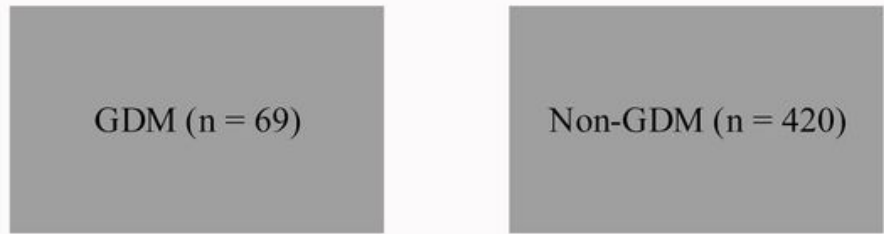

\section{Figure 1}

Study flow diagram. BMI, Body mass index; DBP, Diastolic blood pressure; EAT, Epicardial adipose tissue;GDM, Gestational diabetes mellitus; HDL-C, High-density lipoprotein cholesterol; LDL-C, Low-density lipoprotein cholesterol; NICU, Neonatal intensive care unit; OGTT, Oral glucose tolerance test; SBP, Systolic blood pressure. 


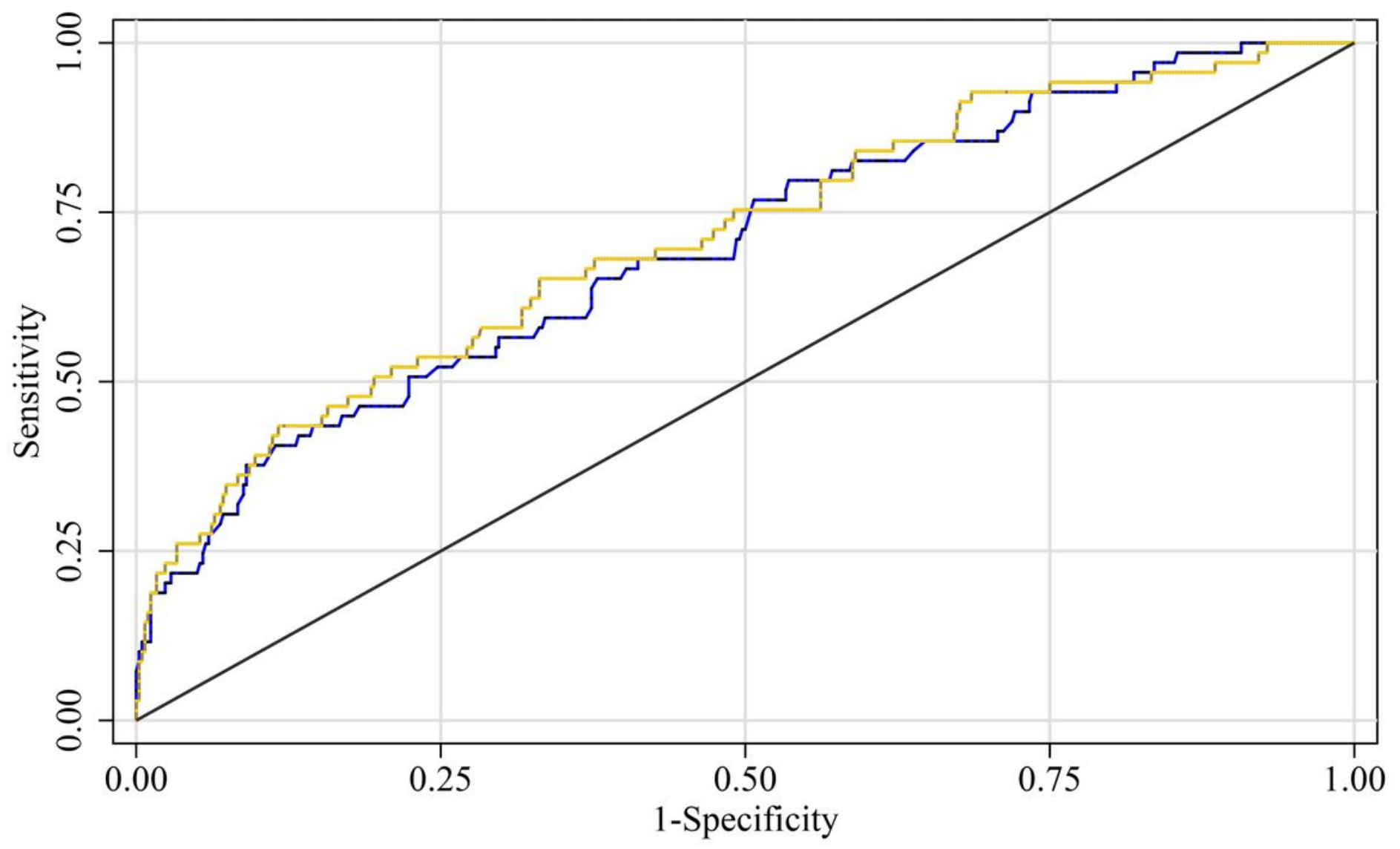

EAT thickness ROC area: 0.698

EAT thickness + HDLC-C ROC area: 0.713

Reference

Figure 2

Receiver operating characteristic (ROC) curves for EAT thickness and HDL-C for the prediction of GDM. EAT, Epicardial adipose tissue; GDM, Gestational diabetes mellitus; HDL-C, High-density lipoprotein cholesterol. 